\title{
PREVALÊNCIA DE LEPTOSPIROSE CANINA EM UM ABRIGO NO MUNICÍPIO DE UBERLÂNDIA MG
}

Eliandra Nunes Santana Araújo1, Eduardo Francisco Ferreira de Andrade", Patrícia Alves Teixeira², Danilo Guedes Junqueira Júnior ${ }^{3}$

${ }^{1}$ Bacharel em Medicina Veterinária do Centro Universitário do Triângulo, Uberlândia-MG, Brasil.

2 Professora Mestre do curso de Medicina Veterinária do Centro Universitário do Triângulo, Uberlândia-MG, Brasil.

${ }^{3}$ Professor Doutor do curso de Medicina Veterinária do Centro Universitário do Triângulo, Uberlândia-MG, Brasil.

E-mail de contato: dan_hp2002@yahoo.com.br

Recebido em: 15/02/2020 - Aprovado em: 15/03/2020 - Publicado em: 30/03/2020 DOI: 10.18677/EnciBio_2020A19

\begin{abstract}
RESUMO
A leptospirose é uma doença comum em locais urbanizados sem saneamento básico, e a prevalência é maior nos países tropicais com altas precipitações pluviais e onde o solo é neutro ou alcalino. A bactéria causadora é transmitida pelos roedores e pode contaminar os cães, e até mesmo as pessoas, sendo a enfermidade considerada uma zoonose. O objetivo deste artigo foi verificar a soroprevalência da leptospirose em cães em um abrigo na cidade de UberlândiaMG. Foram coletadas amostra de sangue 25 animais, representando $10,5 \%$ (25/240) da população total do abrigo, entre fêmeas e machos, adultos com idade de três a 10 anos. Todos animais foram não reagentes, resultado importante visto se tratar de um ambiente de adensamento populacional e propício a presença de roedores. As estratégias de manejo integrado de roedores e a vacinação tiveram impacto direto na prevalência desta zoonose.
\end{abstract}

PALVRAS-CHAVE: Educação ambiental; Rattus novergicus, vacinação.

\section{PREVALENCE OF CANINE LEPTOSPIROSIS IN A SHELTER IN THE MUNICIPALITY OF UBERLÂNDIA MG}

\begin{abstract}
Leptospirosis is a common disease in urbanized places without basic sanitation, and its prevalence is higher in tropical countries with high rainfall and where the soil is neutral or alkaline. The causative bacteria is transmitted by rodents and can infect dogs, and even people, the disease is considered a zoonosis. The objective of this article was to verify the prevalence of leptospirosis in dogs in a shelter in the city of Uberlândia-MG. 25 animals were collected, between females and males, adults aged 3 to 10 years. All animals were non-reactive, an important result since it is a densely populated environment and conducive to the presence of rodents. Strategies for integrated rodent management were effective as a direct impact on the prevalence of this zoonosis.
\end{abstract}

KEYWORDS: Environmental education, Rattus norvegicus. vaccination. 


\section{INTRODUÇÃO}

Segundo Chaiblich et al. (2017) a leptospirose é uma zoonose, com distribuição mundial causada por uma bactéria gram-negativa do gênero Leptospira, com baixa letalidade, podendo ter sinais clínicos assintomáticos até severos. A Leptospirose no continente americano principalmente na América do Sul é um grande problema para saúde pública devido as condições climáticas sendo o Brasil um dos países com maior número de casos registrados (ELBER et al., 2018).

Como Leptospira precisa de água, a incidência em períodos chuvosos é maior devido a tendência de aumentar a pluviosidade e enchentes, consequentemente a prevalência é maior em regiões tropicais (BUFFON, 2018). Conforme o trabalho realizado por Balamurugan et al. (2018) a leptospirose apresenta prevalências mais altas em estados litorâneos tanto em animais quanto em humanos.

O gênero Leptospira foi dividido em duas espécies: cepas patogênicas que são as $L$. interrogans sensu lato e as cepas saprófitas que são as $L$. biflexas sensu lato (MEHROTRA et al., 2017). De acordo com Himani et al. (2013) há 13 leptospiras patogênicas e mais de 260 sorovares, sendo os mais comuns que infectam cães o sorovar canicola e o sorovar icterohaemorragia, no entanto os cães podem ser infectados por outros sorovares.

De acordo com Brasil (2017) os principais animais que são portadores da leptospira são os roedores, tendo destaque a espécie Rattus norvegicus que é portador do sorovar mais patogênico para humanos Icterohaemorragiae. Estes animais não desenvolvem a doença, porém, quando são infectados, ficam com a bactéria nos rins e acabam as eliminando no ambiente pela urina, podendo contaminar a água, solo e alimentos.

Segundo Mesquita et al. (2016) animais domésticos e o humano se comportam como portadores acidentais da bactéria, com a possibilidade de infectarse e desenvolver a doença, os cães podem ser uma fonte de infecção da bactéria e serem reservatórios, pois tem um alto potencial de transmissão da doença para a espécie humana.

Leptospiras são transmitidas entre hospedeiro por contato direto com urina infectada, transferência placentária, ingestão de tecidos infectados e por transmissão indireta que é mais comum através de fontes de água e alimentos contaminados (BALAMURUGAN et al.,2018).

Para a realização do diagnóstico são utilizados exames sorológicos, microbiológicos e moleculares, também para a conclusão do diagnóstico considerase a anamnese, sinais clínicos aparentes e os exames hematológicos do animal. Para a Organização Mundial de Saúde o teste recomendado para confirmação da leptospirose é a soroaglutinação Microscópica que detecta os anticorpos aglutinantes, através da reação das diluições de soro do animal com leptospiras vivas (HAGIWARA, et al. 2015).

Um problema progressivo no Brasil é o aumento de cães abandonados e consequentemente a superlotação dos abrigos coletivos, tornando assim uma situação preocupante, pois os animais assintomáticos são fontes de infecções nas baias, uma vez que, esses eliminam a bactéria na urina infectando os outros animais.

A característica zoonótica da doença é de grande importância para os tratadores e os futuros adotantes que poderão ser expostos. Por isso Reis et al. (2017) sugerem que animais que vivem em regiões propicias à infecção devem ser investigados quanto a doença. Deste modo, objetivou-se avaliar a prevalência de 
Leptospirose em um abrigo de animais no município de Uberlândia- MG e verificar a efetividade de estratégias de prevenção adotadas.

\section{MATERIAL E MÉTODOS}

O presente estudo foi realizado na APA (Associação de Proteção Animal), no município de Uberlândia, estado de Minas Gerais, Brasil. Os animais atendidos pela APA são animais que sofreram maus-tratos, abandono ou algum tipo de violência. Vivem no abrigo 240 cães adultos que são mantidos em baias coletivas e são alimentados com ração e água ad libitum.

O presente estudo teve os procedimentos avaliados e aprovados pelo Conselho de Ética no Uso de Animais/Unitri sob protocolo 47/2017-2. Foram coletadas amostras de sangue por venopunção nas veias safenas do membro pélvico ou veia cefálica do membro torácico de 25 animais da espécie canina sem raça definida, sendo aleatório a coleta entre machos e fêmeas adultos com idade aproximadamente entre três a 10 anos, optando pelos animais mais dóceis com o objetivo de evitar métodos de contenção.

Os cães selecionados estavam distribuídos em três setores de baias, sendo setor laranja e verde com 60 cães cada e setor azul com 120 animais. Optou-se por uma seleção sistemática dos cães a intervalos de 10 animais até que se alcançasse 25 animais coletados ou 10\% da população total de adultos do abrigo.

Foram utilizadas seringas descartáveis com a medida de $3 \mathrm{~mL}$ e agulha com calibre de $25 / 7$ e tubo para bioquímica sem anti-coagulante e devidamente armazenados. Para obtenção do soro sanguíneo as amostras foram centrifugadas e depositadas em tubos de microaglutinação e armazenadas a uma temperatura de $-20^{\circ} \mathrm{C}$ até a realização do exame.

As amostras foram submetidas ao teste de SAM (Soroaglutinaçao Microscópica) com a diluição inicial de $4,9 \mathrm{~mL}$ de salina $+10 \mathrm{~L}$ de soro do animal testado (1:50). Uma próxima diluição foi feita, utilizando $20 \mathrm{~L}$ da diluição anterior + $20 \mathrm{~L}$ de antígeno vivo (1:50). Amostras foram transferidas para uma placa de microaglutinação e incubadas na estufa a $37^{\circ} \mathrm{C}$ por duas horas. A leitura do teste foi realizada na diluição de 1:100 em microscópio de campo escuro.

Amostras com atividade aglutinante foram testadas contra antígeno reativo usando diluições em série de razão dois até que o título mais alto fosse obtido, para identificar o sorovar infectante. As amostras com título mínimo de 100 foram consideradas positivas. Foram utilizados 12 sorovares vivos de Leptospiras spp. Do Laboratório de Leptospirose do Departamento de Medicina Veterinária Preventiva (DMVP) da UEL: Bratislava, Butembo, Castellonis, Canicola, Grippotyphosa, Icterohaemorrhagiae, Copenhageni, Pomona, Pyrogenes, Hardjo, Wolffi e Tarassovi.

Análise estatística utilizada foi Prevalência de animais infectados. Prevalência aparente $(\mathrm{Pa})$ e real $(\mathrm{Pr})$ foram calculadas conforme Noordhuizen (1997). A Pa foi obtida ponderando-se a frequência com o peso que cada propriedade tem em número de animais em relação ao total de propriedades (fator de ponderação). Os valores de Pr foram estimados ajustando-se o valor de Pa para especificidade $(0,97)$ e sensibilidade $(0,82)$ de teste de SAM (CUMBELAND et al., 1999).

$$
\operatorname{Pr}=(P a+E s p-1) /(\text { Sen }+ \text { Esp-1), onde: }
$$

Sen $=$ sensibilidade do teste

$\mathrm{Pa}=$ prevalência aparente

$E s p=$ especificidade do teste 
Os intervalos de confiança (IC) das prevalências aparente e real dos animais foram calculados para a confiança de $95 \%$ conforme Martin et al. (1987), pela seguinte fórmula:

IC = valor estatístico $\pm\left(z^{*} E P\right)$, onde:

$$
z=1,96(\text { SAMPAIO , 2007) }
$$

$\mathrm{EP}=$ Erro-Padrão

A base de dados, assim como a construção de tabelas e gráficos foram feitas através de planilhas eletrônicas do programa Microsoft Excel versão 2013. Na base de dados, de cada amostra de soro sanguíneo possui o município, data da coleta, idade, raça, sexo, espécie e resultados de SAM.

\section{RESULTADOS E DISCUSSÃO}

Foi realizado exame de Soroaglutinação Microscópica (SAM) em amostras de sangue de 25 cães mantidos no abrigo no município de Uberlândia-MG e todos foram soronegativos.

Castro et al. (2011a) na cidade de Uberlândia encontraram os sorovares Autumnalis, Tarassovi, Canicola e Gripptophytosa com uma prevalência de 34,2\%, $23,7 \%, 17,1 \%$ e $14,5 \%$ respectivamente. Os resultados foram obtidos através da coleta de sangue dos animais durante a campanha de vacinação anti-rábica e os sorovares Autumnalis e Tarassovi, foram também detectados em humanos no ano de 2008 que pode ser explicado através do fato do grande contato entre os humanos e os cães. Os autores apontaram ainda que os dados podem estar subestimados devido à grande quantidade de animais assintomáticos, mas afetados cronicamente.

Bier et al., (2013) encontraram uma prevalência de $27,80 \%$ utilizando 378 amostras, sendo que destas 105 foram consideradas positivas em Vila Pantanal Curitiba, Paraná onde o saneamento básico é precário, e de constante alagamento e acúmulo de lixo favorecendo a permanência e o risco de expansão da doença visto que a população total de cães foi estimada em 845 e muitos podem encontrase assintomático, mas mantendo a transmissão.

Em Porto Alegre no Rio Grande do Sul Mesquita et al., (2016) coletaram 142 amostras de sangue dentre estas 26 foram consideradas positivas tendo encontrado soropositividade para os sorovares Canicola e Icterhaemorragiae, sendo $27 \%$ e $46 \%$ respectivamente. Também foi aplicado um questionário na comunidade para os tutores dos animais coletados que mencionaram que os mesmos não foram vacinados e apresentavam uma baixa percepção sobre os riscos e fontes de contaminação.

A prevalência varia de acordo com cada região e país estudado, sendo os países de climas tropicais os com maior prevalência devido ter a temperatura ideal para a sobrevivência da bactéria, a ausência de animais reagentes no presente estudo contrasta com um cenário da presença de fatores de risco com aglomeração de animais.

A APA mantém esses cães realizando um trabalho voluntário com finalidade de garantir bem-estar e no retorno a companhia de novos tutores. Está localizada em área classificada como urbana, todavia é uma região as bordas da cidade em região de chácaras e rodovias com saída para municípios da região, sendo um ambiente periurbano que possibilita maior contingente de roedores. 
Uma das razões para a ausência de animais reagentes pode estar no programa de manejo integrado de roedores executado. Por meio de projeto de extensão universitária foram instaladas 40 portas iscas em todo o abrigo os quais são vistoriados periodicamente para evidenciar consumo da isca, reposição e presença de roedores no ambiente.

Conjuntamente foi executado descarte de resíduos sólidos acumulados no abrigo como gaiolas, caixas plásticas, sacos e sacolas, materiais esses que podem ser empregados pelos roedores para constituição de abrigos. Além de orientação aos cuidadores sobre uso de equipamentos de proteção individual, como identificar a presença de roedores em baias e informações sobre a leptospirose.

A vacinação é considerada uma ferramenta importante na profilaxia induzindo proteção contra a doença clínica e previne a transmissão dessa zoonose ao humano (CASTRO et al., 2011b). Todos os animais do abrigo haviam sido imunizados sete meses antes do presente estudo contra sorovares Canicola, Icterohaemorrhagiae, Pomona, Grippothyphosa e Copenhageni (Vacina V11Elevencell, Labovet) fato que auxilia no controle da doença e a transmissão aliada ao manejo de outros hospedeiros como no caso dos roedores.

A imunidade pós-vacinal pode durar entre seis e oito meses, sendo os títulos aglutinantes indetectáveis pela técnica de SAM a partir de 90 dias após a vacinação, independente do sorovar (CASTRO et al., 2011b). Isso explica o fato de animais mesmo imunizados não terem sido detectados no presente estudo. Vale destacar que mesmo na vigência de baixos títulos da resposta vacinal, a exposição de cães ao antígeno vivo resulta em elevação dos títulos de anticorpos protetores (LANGONI et al., 2002).

Com base nas amostras coletadas e seus resultados negativos, pode-se perceber a importância do acompanhamento de um profissional da área de veterinária na saúde animal e humana. A escolha dos métodos de prevenção e controle tiveram impacto positivo sendo importantes para prevenir a transmissão da leptospirose garantindo ambiente seguro e de bem-estar aos cães abrigados.

\section{REFERÊNCIAS}

BALAMURUGAN, V., ALAMURI, A., BHARATHKUMAR, K., PATIL, S.S., GOVINDARAJ, G.N. et al. Prevalence of Leptospira serogroup-specific antibodies in cattle associated with reproductive problems in endemic states of India. Tropical Animal Health and Production, p. 1131 - 1138, 2018. Disponível em: https://doi.org/10.1007/s11250-018-1540-8.

BIER, D., SHIMAKURA, S.E., MORIKAWA, V.M., ULLMANN, L.S., KIKUTI, M. et al. Análise espacial de risco de leptospirose canina na Vila Pantanal, Curitiba, Paraná. Pesquisa Veterinária Brasileira. V. 33, n. 1, p. 74-79, 2013. DOI: 10.15910/S0100-736X2013000100013.

BRASIL. Ministério da Saúde. Secretaria de Vigilância em Saúde. Guia de Vigilância em Saúde. Brasília: Ministério da Saúde, 2017. Disponível em: http://portalarquivos.saude.gov.br/images/pdf/2017/outubro/06/Volume-Unico2017.pdf

BUFFON, E. A. M. Vulnerabilidade socioambiental à leptospirose humana no aglomerado urbano metropolitano de Curitiba, Paraná, Brasil: proposta metodológica a partir da análise multicritério e álgebra de mapas. Saúde e Sociedade, 27, 588-604, 2018. 
CASTRO J.R., SOUZA M.A., SALABERRY S.R.S., GUIMARÃES E.C. \& LIMARIBEIRO A.M.C. Cinética da resposta imune humoral de cães jovens imunizados contra Leptospira interrogans. Pesquisa Veterinária Brasileira. v.31, n.11, p. 10001005, 2011b. Disponível em: http://dx.doi.org/10.1590/S0100-736X2011001100011

CASTRO, J. R.; SALABERRY, S. R. S.; SOUZA, M. A.; LIMA-RIBEIRO, A. M. C. Sorovares de Leptospira spp. pedrominantes em exames sorológicos caninos e humanos no munícipio de Uberlândia, Estado de Minas Gerais. Revista da Sociedade Brasileira de Medicina Tropical. 44(2) p. 217-222. $2011 \mathrm{a}$. Disponível em: http://www.scielo.br/scielo.php?pid=S003786822011005000012\&script=sci_abstract \&tlng=pt DOI: $10.1590 /$ S0037-86822011005000012

CHAIBLICH, J. V.; LIMA, M. L. S.; de OLIVEIRA, R. F.; MONKEN, M.; PENNA, M. L. F. Estudo espacial de riscos à leptospirose no município do Rio de Janeiro (RJ). Saúde Debate. Rio de janeiro, v. 41, n. especial, p. 225-240, 2017. Disponível em: https://www.scielosp.org/pdf/sdeb/2017.v41 nspe2/225-240. DOI: 10.1590/010311042017 S219

CUMBERLAND, P.; EVERARD, C.O.R.; LEVETT, P.N. Assessment of the efficacy of an IgM-ELISA and microscopic agglutination test (MAT) in the diagnosis of acute leptospirosis. The American Journal Tropical Medicine. Hygiene. 61(5):731- 734, 1999.

Disponível

em: https://www.researchgate.net/publication/12714221_Assessment_of_the_efficacy_of _IgM_ELISA_and_microscopic_agglutination_test_MAT_in_the_diagnosis_of_acute_ leptospirosis DOI: 10.4269 / ajtmh.1999.61.73̄1

ELBER, O. R. et al. Prevalencia y factores de riesgo relacionados com leptospirosis canina enel municipio de Soledad em el departamento del Atlántico. Revista Edufisica.com Ciencias Aplicadas al Deporte, v. 10, n. 21, p. 27-37, 2018. Disponível em: http://revistas.ut.edu.co/index.php/edufisica/article/view/1255/972

HAGIWARA M.K., MIOTTO B.A. \& KOGIKA M.M. Leptospirose. In: Tratado de medicina interna de cães e gatos (eds. by Jericó MM, Neto JPA \& Kogika MM), pp. 2678-708. Roca, Rio de Janeiro, Brasil. 2015.

HIMANI, D.; SUMAN, M. K.; MANE, B. G. Epidemiology of leptospirosis: an Indian perspective. Journal Foodborne Zoonotic Diseases. n. 1, v. 1, p. 6-13, 2013. Disponível

em: https://pdfs.semanticscholar.org/3f31/932ad84fce28827f2395eb44cbc1da92f71a.pdf

LANGONI H., PIMENTEL V.L., SILVA A.V., LUCHEIS S.B.; DENARDI M.B. Avaliação da dinâmica de anticorpos pós-vacinais contra Leptospira spp. em cães vacinados pela prova de SAM. Ars Vet. v.18, p.54-61, 2002.

MEHROTRA, P., RAMAKRISHNAN, G., DHANDAPANI, G., SRINIVASAN, N., \& MADANAN, M. G. Comparison of Leptospira interrogans and Leptospira biflexa genomes: analysis of potential leptospiral-host interactions. Molecular BioSystems, 13(5), 883-891, 2017. doi:10.1039/c6mb00856a 
MESQUITA, M. O.; TREVILATO, G. C.; SARAIVA, L. H.; SCHONS, M. S.; GARCIA, M. I. F. Material de educação ambiental como estratégia de prevenção da leptospirose para uma comunidade urbana reassentada. Caderno saúde coletiva. Rio de Janeiro, v. 24, n. 1, 2016.2 Disponível em: http://www.scielo.br/scielo.php?script=sci_abstract\&pid=S1414462X2016000100077 \&lng=en\&nrm=iso\&tlng=pt DOI: $10.1590 / 1414-462 X 2016000 \times 0428$

REIS, M. O.; CAPRIOLI, R. A.; LAISSE, C. J. M.; GUIMARÃES, L. L. B., ANDRADE, C. P. et al. Surto de leptospirose em bezerros criados em revesta de arroz. Pesquisa Veterinária Brasileira. 37(9):937-940, 2017. Disponível em: http://www.scielo.br/scielo.php?pid=S0100736X2017000900937\&script=sci_abstract \&tlng=pt DOI:10.1590/S0100-736X2017000900007

SAMPAIO, M.B.I., Estatística Aplicada à Experimentação Animal. Vol.1. 3르 ed. FEP-MVZ, Belo Horizonte, p. 264. 2007

SIMÕES, S. L.; SASAHARA, T. H. C.; FAVARON, P. O.; MIGLINO, M. A. Leptospirose Revisão, PUBVET, Maringá, v.10, n. 2, p. 138-146, 2016. Disponível em: http://www.pubvet.com.br/artigo/2694/leptospirose-ndash-revisatildeo ISSN: 1982-1263 DOI:10.22256/pubvet.v10n2.138-146 